\section{Physiological Acclimation of Taxodium Hybrid 'Zhongshanshan 118' Plants to Short-term Drought Stress and Recovery}

Qin Shi, Yunlong Yin, Zhiquan Wang, Wencai Fan, and Jianfeng Hua ${ }^{1}$ Institute of Botany, Jiangsu Province and Chinese Academy of Sciences, Nanjing 210014, Jiangsu, China

Additional index words. Taxodium hybrid, physiological acclimation, drought stress, recovery, water relations

\begin{abstract}
The physiological acclimation of Taxodium hybrid 'zhongshanshan 118' (T.118) plants to a progressive drought stress and drought-stressed to recovery treatment (DS-R) was investigated in this study. Plants of control (C) treatment were watered daily throughout the experiment. Results indicated that water deficit reduced stomatal conductance $\left(g_{\mathrm{S}}\right)$ to improve water use efficiency (WUE) and, as a consequence, net photosynthetic rate $\left(P_{\mathrm{n}}\right)$, transpiration rate $\left(T_{\mathrm{r}}\right)$, and intercellular $\mathrm{CO}_{2}$ concentration $\left(C_{\mathrm{i}}\right)$ were also decreased in DS-R T.118 plants compared with $C$ plants. These reductions became more significant with decreasing soil water availability. Correlation analysis showed $g_{\mathrm{S}}$ was positively correlated $(P<0.01)$ with the soil water content as well as leaf relative water content (RWC). There was a tendency to accumulate proline, malondialdehyde (MDA), antioxidases, and membrane electrolyte leakage as stress intensity increased. Moreover, drought stress induced significant $(P<0.05)$ decline in total chlorophyll contents $\left(\mathrm{Chl}_{t}\right)$ and increase of nonphotochemical quenching (NPQ) on day 8 as a photo-protective mechanism. Cluster analysis distinguished the adaption of $T .118$ plants to water deficit in two ways. First, photosynthesis was related to thermal dissipation, and second antioxidation was related to morphology and osmosis. Furthermore, tested parameters showed a reversed tendency and restored equivalently to $C$ levels after 9 days of rewatering. These findings suggest that $T .118$ plants demonstrated considerable tolerance to short-term drought stress and recovery due to a high degree of plasticity in physiological acclimation.
\end{abstract}

Drought is defined as soil and/or atmospheric water deficit, and is one of the main factors determining plants growth, vitality, and productivity (McDowell, 2011). According to scientific data, losses in growth and productivity of plants caused by water deficit may exceed the losses inflicted by all other adverse situations combined (Allen et al., 2010). More seriously, predictions of climate change for many regions reveal an intensification of water deficit, making it much more crucial to improve drought tolerance of plants.

Plants have evolved various mechanisms to confront low water availability (McDowell, 2011). Perennial herbs, for instance, can reduce water loss through inhibited transpiration by reducing leaf area, closing stomata, and leaf

Received for publication 2 June 2016. Accepted for publication 2 Aug. 2016.

This paper was financially supported by the National Natural Science Foundation of China (no. 31570593), the Program of Innovation Capacity Construction of Jiangsu Province (no BM2015019), and the Agricultural Science and Technology Innovation Project of Jiangsu Province (no. CX132046)

${ }^{1}$ Corresponding author. E-mail: jfhua2009@gmail. com.

HortScience Vol. 51(9) September 2016 2011).
As a matter of fact, tolerance of drought is defined as a comprehensive capacity integrating both drought and recovery (Chen et al., 2015). Despite the universal understanding of plant responses to drought, behaviors regarding rehydration are distinguished (Laanisto and Niinemets, 2015). Plant ability to resume photosynthesis, turgor pressure, leaf rehydration, and cellular metabolic function had been considered as postdrought recovery (Luo et al., 2011). Meanwhile, plant carbon balance and subsequent bio-physiological restoration depends on the rates and extent of photosynthesis recovery (Chen et al., 2015; Souza et al., 2004). For drought-tolerant species, this defense and adaptation to water deficit will be rapidly reversible when stress is relieved to avoid permanent dysfunction (Yazaki et al., 2015). Therefore, the recuperative potential from drought stress is a vital aspect in terms of plant vitality and survival (Gallé et al., 2007). To improve drought tolerance, plant breeders often use hybridization to improve vigor and heterosis. These characteristics are commonly recognized as the superiority of hybrids relative to parental performance (Perron, 2008). To date, one of the most studied species is maize (Zea mays), which had been successfully exploited to enhance drought tolerance by creation of hybrids (Lopes et al., 2011). As demonstrated, horticulture plants in arid and semiarid regions are usually scarce, and drought-tolerant horticulture trees are crucial due to their unique services and resources in function and aesthetics, respectively (Fischer et al., 2009).

The genus Taxodium has historically been recognized as containing three species: Taxodium distichum (L.), Taxodium ascendens, Taxodium mucronatum (Tsumura et al., 1999). However, recent nomenclature places Taxodium as one species with three genotypes: T. distichum Rich. var. distichum (baldcypressBC), T. distichum var. mexicanum (Carriere Gordon) (Montezuma cypress-MC) and $T$. distichum var. imbricarium (Nutt.) Croom (pondcypress-PC) (Adams et al., 2012; Creech et al., 2011; Denny and Arnold, 2007). For the purpose of this study, we have accepted the nomenclature that combines all Taxodium associates into one species with three botanical varieties (Zhou et al., 2010). In China, 'Zhongshanshan' is an accepted term that describes the range of hybrids created by crosses between BC, MC, and PC. For instance, T.118 is the result of a backcrossed generation [ $(\mathrm{BC} \times$ $\mathrm{MC})$ 우 $\left.\times \mathrm{MC}^{1}\right]$ made in 1990s and selected in 2004 at the Nanjing Botanical Garden (Yin and $\mathrm{Yu}, 2005)$. Field afforestation of $T .118$ plants in this decade indicated heterobeltiosis in growth rate and environmental adaptability. Currently, T.118 plants have been widely used as timber, windbreak, and horticulture plantations in coastal and urban areas in southeastern China (Qi et al., 2014). As Creech et al. (2011) reported, Montezuma cypress can resist considerable magnitude drought stress. Meanwhile, a recent silviculture trial of $T .118$ plants in the hydro-fluctuation belt of the Three Gorges Reservoir, where soil conditions may be 
extremely dry after water levels drop, has demonstrated a survival rate greater than $90 \%$ (Yin et al., 2014). However, the ability of $T .118$ plants to cope with the anticipated decrease in water availability and its recuperative potential is still poorly understood.

Further understanding of physiology of both drought tolerance and recovery capacity will be instrumental in selecting specific biological traits for breeding. Thus, we assessed the temporal dynamics and interactions of $T .118$, which were based on successive decrease of soil moisture to identify changes induced by drought stress and recovery.

\section{Material and Methods}

Plant materials and experiment design. The experiment was carried out in a greenhouse located in Nanjing Botanical Garden $\left(32^{\circ} 3^{\prime} \mathrm{N}, 118^{\circ} 49^{\prime} \mathrm{E}\right)$. Rooted cuttings of 2-year-old $T .118$ plants were grown under natural conditions from May to July 2015 in plastic pots containing 3:1:1 (v/v/v) clay, vermiculite, and perlite. Each plant was grown in a $7.2 \mathrm{~L}$ pot $(23 \mathrm{~cm}$ upper diameter, $15 \mathrm{~cm}$ basal diameter, and $22 \mathrm{~cm}$ high) under fully irrigated conditions $(27.2 \% \mathrm{v} / \mathrm{v}, \approx 75 \%$ of maximum pot capacity). They were allowed to acclimate to the natural conditions for $60 \mathrm{~d}$ before imposing the treatments. After the last watering on 26 July, 18 plants of similar growth (average $45 \mathrm{~cm}$ in height, $6.7 \mathrm{~mm}$ in basal diameter) were transferred to a greenhouse and assigned to two different treatments, each of which included nine replications. The C treatment was watered daily to previous pot capacity throughout the experiment. Droughtstressed to recovery (DS-R) treatment received no water irrigation for $8 \mathrm{~d}$, after which all plants were rewatered daily to previous pot capacity for another $9 \mathrm{~d}$ for the recovery phase. The experiment was designed in a completely randomized block. The imposition of drought simulates what may be anticipated to occur in the field.

Temperature and relative humidity of the greenhouse was measured three times a day (0900, 1200, and $1600 \mathrm{HR})$. A sunshade net with uniform pore size was placed at the top of the greenhouse to avoid direct sunlight exposure. During the experiment, when temperatures in the greenhouse exceeded $30{ }^{\circ} \mathrm{C}$, two giant radiator fans on the wall were turned on to cool in order to avoid inhomogeneous aeration. Volumetric water content was monitored daily at $1800 \mathrm{HR}$ within the first $8 \mathrm{~cm}$ from the substrate surface in each pot throughout the experiment with a soil moisture detector (SM-2, China).

Specific leaf area and water content. On days $5,8,10$, and 17 of the experimental period (Fig. 1), mature and fully expanded leaves were sampled. To minimize the destructive effect on plants, every three of nine plant leaves were collected and mixed uniformly for one replication, and thus, three replicates were assigned in sample collection. Leaf areas were determined by a laser scanner (Epson Perfection V700, Japan) with

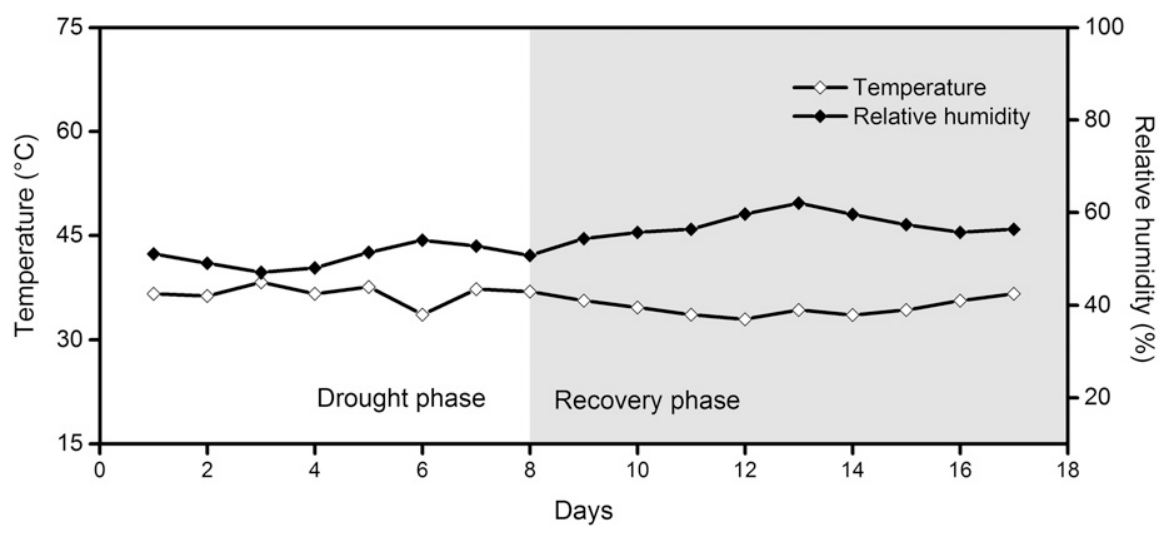

Fig. 1. Mean of daily temperature $\left({ }^{\circ} \mathrm{C}\right)$ and relative humidity $(\%)$ in greenhouse.

WinRHIZO Software (Regent Instruments Inc., Canada). Specific leaf area (SLA) was calculated as the ratio of leaf area to leaf dry weight (DW). Leaves were weighed to determine the fresh weight (FW) and then floated on distilled water in petri dishes for $24 \mathrm{~h}$ to regain turgidity. After that, leaves were reweighed [turgid weight (TW)] without excess water and DW was measured after dried at $75{ }^{\circ} \mathrm{C}$ for $24 \mathrm{~h}$ (Rouphael et al., 2008). RWC was calculated as (FW - DW/ TW - DW) $\times 100 \%$.

Chlorophyll content. A total of $0.2 \mathrm{~g}$ fresh leaf was dispersed evenly in $95 \%$ ethyl alcohol at room temperature in the dark for $24 \mathrm{~h}$. The $\mathrm{Chl}_{\mathrm{t}}$ was calculated according to Ritchie (2008) by determining the absorbance at 649,652 , and $665 \mathrm{~nm}$ with a spectrophotometry (Jasco ultraviolet-visible, Japan).

Proline content. A total of $0.2 \mathrm{~g}$ fresh leaf was dispersed evenly in $3 \%$ aqueous sulfosalicylic acid and heated at $100{ }^{\circ} \mathrm{C}$ for $10 \mathrm{~min}$. Concentration of proline was then determined in this extract by acid-ninhydrin reagent method on a DW basis (Bates et al., 1973).

Relative electrolyte leakage. A total of $0.2 \mathrm{~g}$ fresh leaf was immersed in a tube with $15 \mathrm{ml}$ distilled water. The tube was centrifuged for $50 \mathrm{~s}$ and then electrical conductivity $\left(\mathrm{EC}_{1}\right)$ of the extract was determined by a conductivity meter (DDS-11A, China). Thereafter, the tube was put in a boiling water bath for $10 \mathrm{~min}$. After chilling to an ambient temperature, $\mathrm{EC}_{2}$ was measured. The relative electrolyte leakage (REL) of the leaf was calculated as $\mathrm{EC}_{1} / \mathrm{EC}_{2}$ (Blum and Ebercon, 1981).

Antioxidant enzyme activities and MDA. Under ice-cold conditions, $0.2 \mathrm{~g}$ fresh leaf was ground with $5 \mathrm{~mL}$ phosphate buffer $(\mathrm{pH} 7.8)$ and then centrifuged at the rotating speed of $12,000 \mathrm{rpm}$ for $20 \mathrm{~min}$ at $4{ }^{\circ} \mathrm{C}$. The supernatant was extracted to measure enzyme activities. Superoxide dismutase (SOD) activity was assayed by defining the amount of enzyme that inhibited the rate of nitroblue tetrazolium by $50 \%$ at $560 \mathrm{~nm}$. Catalase (CAT) activity was assayed by measuring the induction of hydrogen peroxide at $1 \mathrm{~min}$ intervals in $3 \mathrm{~min}$ at $240 \mathrm{~nm}$. The activity of peroxidase (POD) was determined with guaiacol as the substrate. An increase in absorbance was also recorded at 1 min intervals in $3 \mathrm{~min}$ at $470 \mathrm{~nm}$. For measurement of MDA concentration, $2 \mathrm{~mL}$ of previous supernate was extracted with $0.67 \%$ thiobarbituric acid. The admixture was heated in a boiling water bath for $30 \mathrm{~min}$ and then promptly refrigerated in an ice bath before being centrifuged at $3000 \mathrm{rpm}$ again for $10 \mathrm{~min}$. The absorbance was recorded at 532, 600, and $450 \mathrm{~nm}$, respectively (Sharma et al., 2011).

Photosynthesis and fluorescence. On days $5,8,10$, and 17 of the experimental period, six of nine plants per treatment were chosen to measure net $P_{\mathrm{n}}, T_{\mathrm{r}}, g_{\mathrm{S}}$, and intercellular $\mathrm{CO}_{2}$ concentration $\left(C_{\mathrm{i}}\right)$. A red/blue LED light LI-6400 Portable System (LI-COR, Lincoln, NE) was used at a photosynthetically active radiation of $1200 \mu \mathrm{mol} \cdot \mathrm{m}^{-2} \cdot \mathrm{s}^{-1}$ quantum from 9:30 to 11:00 AM. $\mathrm{CO}_{2}$ concentration, air velocity, and humidity in leaf chamber were fixed at $380 \mu \mathrm{mol} \cdot \mathrm{mol}^{-1}, 0.5 \mathrm{~L} \cdot \mathrm{min}^{-1}$, and $60.0 \%$, respectively. The measurement was performed on leaves chosen from branches that were center located. The ratio of $P_{\mathrm{n}}$ to $T_{\mathrm{r}}$ was calculated as instantaneous WUE.

After the test of photosynthesis, six of nine plants per treatment were chosen to measure chlorophyll fluorescence with a modulated fluorometer (PAM 2100, Effeltrich, Germany). Leaves were irradiated by a saturated impulse (0.8 s) after a 30-min darkness adjustment during which the electron transport was considered to be ceased sufficiently in thylakoid membranes. The three parameters determined were the initial fluorescence $\left(F_{\mathrm{O}}\right)$, maximum fluorescence $\left(F_{\mathrm{m}}\right)$, and the maximal photochemical efficiency of PSII, $\left[F_{\mathrm{v}} / F_{\mathrm{m}}=\left(F_{\mathrm{m}}-\right.\right.$ $\left.\left.F_{\mathrm{O}}\right) / F_{\mathrm{m}}\right]$. Thereafter, leaves were exposed to a series of saturating pulses to measure the maximum fluorescence yield in the lightadapted period $\left(F^{\prime}{ }_{\mathrm{m}}\right)$. Actual PSII efficiency $\left(\varphi\right.$ PSII) was then determined as $\left(F^{\prime}{ }_{\mathrm{m}}-F_{\mathrm{S}}\right) /$ $F^{\prime}{ }_{\text {m }}$, where $F_{s}$ was steady-state fluorescence. NPQ was derived from $\left(F_{\mathrm{m}}-F^{\prime}{ }_{\mathrm{m}}\right) / F^{\prime}{ }_{\mathrm{m}}$ (Toscano et al., 2014).

Growth and biomass. At the end of the experiment on 11 Aug., six of nine T.118 plants were selected to measure the respective height and basal diameter by a tapeline 
and vernier caliper, and then they were harvested and divided into leaves, stems, and roots, respectively. FW of leaves, stems, and roots was measured, and then they were dried at $75^{\circ} \mathrm{C}$ for $48 \mathrm{~h}$ until they reached a constant weight to measure the respective DW.

Statistical analysis. Differences of variables between treatments were tested using independent sample $t$ test for means with unequal variances. Means were compared at a significance level $(P<0.05$ and $P<0.01)$.
Relevancy and cluster analysis among the parameters were studied. The statistical analysis was performed employing SPSS 19.0 (IBM Corporation, Somers, NY). Plotting software was performed by Origin 9.1 pro (Origin Laboratory, Northampton, MA).

\section{Results}

Soil volumetric water content, greenhouse temperature and relative humidity. During the

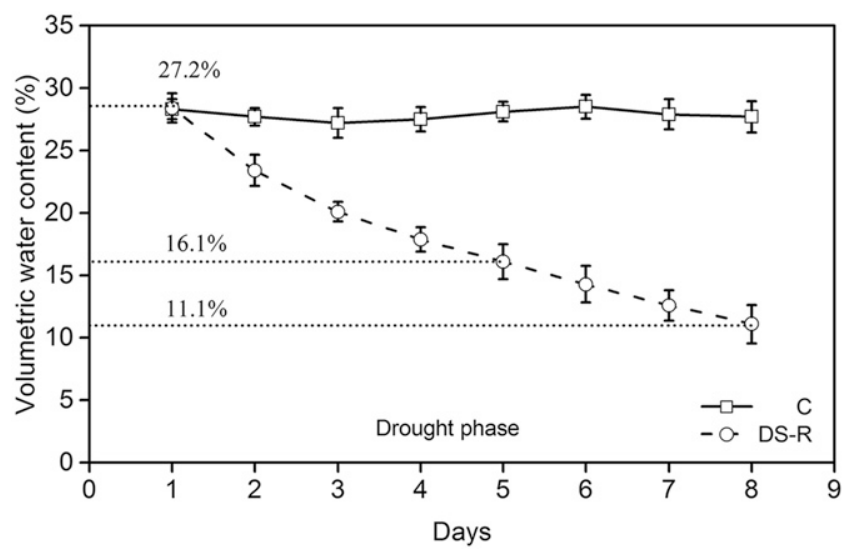

Fig. 2. Time course of pot volumetric water content in drought phase (mean and SE, $n=9$ ).

experiment, no significant fluctuations in daily temperature and relative humidity of greenhouse were observed (Fig. 1). On the first day after watered to pot capacity, soil water content was about $27.2 \%(\mathrm{v} / \mathrm{v})$ in $\mathrm{C}$ and DS-R pots. Then, water content consecutively decreased in DS-R pots with drought duration (Fig. 2). On day 5, soil water content declined to $16.1 \%$ $(\mathrm{v} / \mathrm{v})$ and $T .118$ plants in DS-R treatment showed signs of wilting. On day 8 , it declined to $\approx 11.1 \%(\mathrm{v} / \mathrm{v})$ and plants showed obvious wilting phenomenon; several leaves located on the top branches wilted irreversibly. Thereafter, all DS-R pots were watered to previous pot capacity, starting the recovery phase, while soil water content in $\mathrm{C}$ pots were maintained at about $27.2 \%(\mathrm{v} / \mathrm{v})$ across the experiment.

Temporal dynamics of photosynthetic and fluorescent characteristics. Consistent with the daily temperature and relative humidity, $T .118$ plants in $\mathrm{C}$ treatment showed a stable trend of all measured photosynthetic parameters. Although in DS-R treatments, $P_{\mathrm{n}}, g_{\mathrm{S}}$, and $T_{\mathrm{r}}$ of $T .118$ plants declined consistently with decreasing water availability during drought phase (Fig. $3 \mathrm{~A}-\mathrm{C}) . P_{\mathrm{n}}, g_{\mathrm{S}}$, and $T_{\mathrm{r}}$ differed significantly $(P<0.05)$ between $\mathrm{C}$ and DS-R treatments on days 5 and 8 . Especially on day $8, P_{\mathrm{n}}, g_{\mathrm{S}}$, and $T_{\mathrm{r}}$ in DS-R plants were reduced by $31.3 \%, 25.2 \%$, and $23.1 \%$ compared with $\mathrm{C}$ treatment $(P<0.01)$,

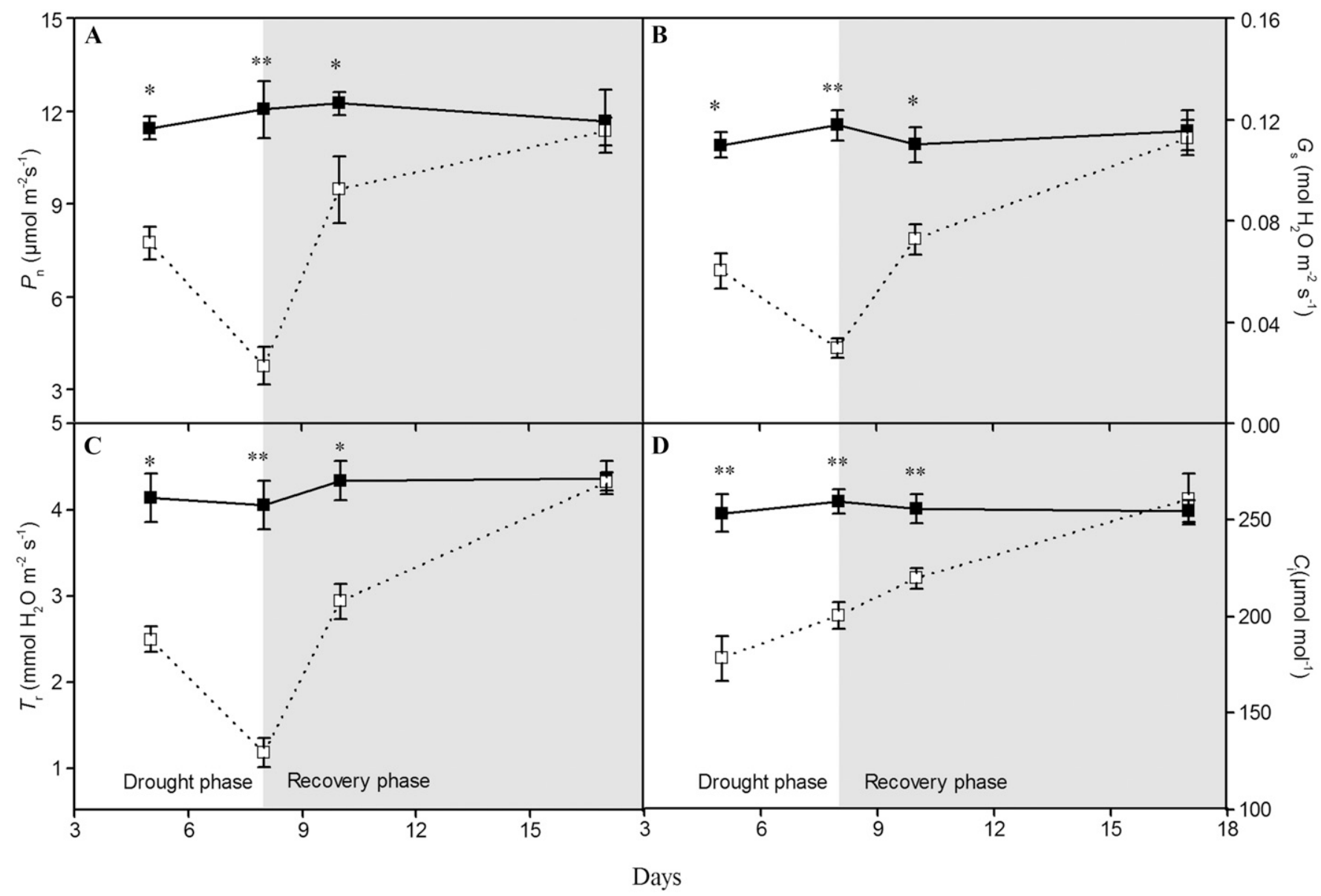

Fig. 3. Variation in mean (and standard error, $\mathrm{n}=6)(\mathbf{A})$ net photosynthetic rate $\left(P_{\mathrm{n}}\right),(\mathbf{B})$ stomatal conductance $\left(g_{\mathrm{s}}\right),(\mathbf{C})$ transpiration rate $\left(T_{\mathrm{r}}\right)$, and $(\mathbf{D})$ intercellular $\mathrm{CO}_{2}$ concentration $\left(C_{\mathrm{i}}\right)$ in $T .118$ of $\mathrm{C}(\square)$, and DS-R $(\square)$ treatments over the course of the experiment. Each square represents samples measured on each sampling day. ${ }^{*}{ }^{* * *} P<0.05, P<0.01$ between treatments, respectively. 
respectively. However, the decreasing of soil availability led to a prominent suppression of $C_{\mathrm{i}}$ on day 5 and it progressively increased as days prolonged (Fig. 3D). After rewatering for $2 \mathrm{~d}$, the photosynthetic responses of $T .118$ plants had recovered but were significantly lower $(P<0.05)$ than $\mathrm{C}$ plants. On day 10, for DS-R plants, $C_{\mathrm{i}}$ continued increasing and was significantly lower $(P<0.05)$ than for $\mathrm{C}$ plants. On day 17 , that is $9 \mathrm{~d}$ since recovery, recovered to $\mathrm{C}$ levels.

$F_{\mathrm{v}} / F_{\mathrm{m}}$ of $T .118$ plants in $\mathrm{C}$ plants was $\approx 0.83$, which was also relatively constant throughout experiment. However, it decreased to 0.81 and $0.79(P<0.05)$ on days 5 and 8 , respectively. On day 10 , the rewatering induced an increase in it, reaching mean values of 0.81 in DS-R plants. On day 17, after recovered for another $7 \mathrm{~d}, F_{v} / F_{m}$ in DS$\mathrm{R}$ plants showed no significant differences compared with C plants (Table 1). Likewise, drought stress induced significant reduction $(P<0.05)$ of $\varphi$ PSII and NPQ on days 5 and 8 , respectively. After being rewatered for $2 \mathrm{~d}$, values of $\varphi$ PSII and NPQ in DS-R plants had increased to an equivalent level of $\mathrm{C}$ plants, and were 0.78 and 1.66, respectively. On day 17 , neither $\varphi$ PSII nor NPQ showed signifiall, $F_{v} / F_{m}$ and $\varphi$ PSII decreased with soil water availability, whereas NPQ behaved oppositely compared with $F_{v} / F_{m}$ and $\varphi$ PSII (Table 1).

Water relation and bio-physiological changes. Leaf WUE, however, was always than $C$ plants on days 5 and 8 (Table 2). After rewatering for $2 \mathrm{~d}$ on day 10 , for DS-R plants, WUE was still maintained at the previous level, whereas on day 17 , that is $9 \mathrm{~d}$ since values of $P_{\mathrm{n}}, g_{\mathrm{S}}, C_{\mathrm{i}}$, and $T_{\mathrm{r}}$ in DS-R plants had cant changes compared with $\mathrm{C}$ plants. Oversignificantly higher $(P<0.05)$ for DS-R plants recovery, WUE in DS-R plants had recovered to C levels. Leaf RWC of T.118 plants in DS$\mathrm{R}$ treatment was $7.52 \%$ and $36.8 \%(P<0.05)$ lower than that in $\mathrm{C}$ plants on days 5 and 8 , respectively. As expected, leaf RWC increased from $56.5 \%$ to $81.5 \%$ on day 10 , but was still significantly lower $(P<0.05)$ than $\mathrm{C}$ plants (Table 2). On the last day of the recovery phase, leaf RWC of DS-R plants increased to $\mathrm{C}$ level with no significant difference. Together with the variation of leaf RWC, values of SLA decreased significantly $(P<0.05)$ on days 5 and 8 , respectively. Although on day 10 during the recovery phase, SLA increased a little compared with day 8 , but was still significantly lower $(P<0.05)$ than that in C plants. On day 17, SLA increased to $60.7 \mathrm{~cm}^{2} \cdot \mathrm{g}^{-1}$ after recovered for $9 \mathrm{~d}$, reaching mean value of $\mathrm{C}$ plants.

Compared with $\mathrm{C}$ plants, leaf $\mathrm{Chl}_{\mathrm{t}}$ of T.118 in DS-R treatment increased by $14.3 \%$ on day 5 and then decreased by $11.5 \%(P<0.05)$ on day 8 (Table 2$)$. In the recovery phase, leaf $\mathrm{Chl}_{\mathrm{t}}$ of $T .118$ plants increased rapidly and no significant difference was found between C and DS-R treatments on days 10 and 17 , respectively. The contents of proline and REL in $\mathrm{C}$ plants increased significantly $(P<0.05)$ on day 5 compared with DS-R plants. On day 8 of DS$\mathrm{R}$ plants, they were almost twice of $\mathrm{C}$ plants and after rewatering, they both showed a decreased tendency. On day 17 , both contents of proline and REL reached a similar level in C plants.

Antioxidant enzymes and MDA activities. Across the experiment, activities of MDA, SOD, POD, and CAT in C plants were relatively constant. On day 5, prolonged drought stress increased MDA, SOD, POD and CAT activities significantly $(P<0.01$,
Fig. 4A-D). As drought intensified on day 8 , they all gradually increased. After $2 \mathrm{~d}$ of rewatering, activities of MDA, SOD, POD, and CAT in DS-R plants were decreased. Compared with $\mathrm{C}$ plants, activities of MDA and SOD in DS-R plants showed no significant differences on day 10, whereas POD and CAT were still significantly higher $(P<$ 0.05 and $P<0.01$, respectively) than $\mathrm{C}$ plants. On day 17 , they all decreased to the equivalent level of $\mathrm{C}$ plants and no statistical differences were found between the two treatments.

Growth and biomass characteristics. At the end of this experiment, significant differences were found in leaf and total FW $(P<$ $0.05)$ as well as root to shoot ratio $(P<0.01)$ in $\mathrm{C}$ and DS-R treatments. Although root, stem, leaf, and total dry weight of $T .118$ plants submitted to $\mathrm{C}$ and DS-R treatments showed no significant difference after recovery (Table 3 ).

Correlation and cluster analysis. To determine the relationship indicative of responses to drought stress and recovery, relevancy between the tested parameters were studied. The interrelated analyses concluded that $g_{\mathrm{S}}$ was positively correlated $\left(r^{2}=\right.$ $0.81, P<0.01)$ with soil water content (Fig. 5A). Such positive correlation $\left(r^{2}=\right.$ $0.65, P<0.01)$ was also found between $g_{\mathrm{S}}$ and leaf RWC (Fig. 5B).

Cluster analysis of seven selected parameters, which illuminate most characteristics of photosynthesis, thermal dissipation, morphology, osmosis, and antioxidation, showed the presence of affinity and dissimilarity degree. The group represented two distinctions of the range, and photosynthesis was more related to fluorescence, while the observed partition in antioxidation was found to be more close to morphology and osmosis (Fig. 6).

Table 1. Fluorescence characteristics of $T .118$ plants during the experiment.

\begin{tabular}{cccccc}
\hline Days & & Treatments & $F_{\mathrm{v}} / F_{\mathrm{m}}$ & $\varphi$ PSII & NPQ \\
\hline Drought & 5 & C & $0.83 \pm 0.01 \mathrm{a}$ & $0.78 \pm 0.01 \mathrm{a}$ & $1.56 \pm 0.08 \mathrm{a}$ \\
& & DS-R & $0.81 \pm 0.01 \mathrm{a}$ & $0.73 \pm 0.01 \mathrm{~b}$ & $1.67 \pm 0.06 \mathrm{a}$ \\
& 8 & C & $0.83 \pm 0.01 \mathrm{a}$ & $0.78 \pm 0.01 \mathrm{a}$ & $1.54 \pm 0.04 \mathrm{~b}$ \\
& & DS-R & $0.79 \pm 0.01 \mathrm{~b}$ & $0.62 \pm 0.01 \mathrm{~b}$ & $2.01 \pm 0.02 \mathrm{a}$ \\
Recovery & 10 & C & $0.83 \pm 0.01 \mathrm{a}$ & $0.78 \pm 0.01 \mathrm{a}$ & $1.55 \pm 0.04 \mathrm{a}$ \\
& & DS-R & $0.81 \pm 0.01 \mathrm{a}$ & $0.78 \pm 0.01 \mathrm{a}$ & $1.66 \pm 0.05 \mathrm{a}$ \\
& \multirow{2}{*}{17} & C & $0.83 \pm 0.01 \mathrm{a}$ & $0.78 \pm 0.1 \mathrm{a}$ & $1.58 \pm 0.02 \mathrm{a}$ \\
& & DS-R & $0.83 \pm 0.01 \mathrm{a}$ & $0.78 \pm 0.01 \mathrm{a}$ & $1.58 \pm 0.02 \mathrm{a}$ \\
\hline
\end{tabular}

$\mathrm{C}=$ control; DS-R $=$ drought-stressed to recovery; $\mathrm{NPQ}=$ nonphotochemical quenching; PSII $=$ photosystem II.

Data are mean $\pm \operatorname{SE}(n=6)$. Different lowercase letters in each column indicate significant differences $(P<$ 0.05 ) between treatments on each sampling day.

\section{Discussion}

\begin{tabular}{|c|c|c|}
\hline \multicolumn{3}{|c|}{ Discussion } \\
\hline \multicolumn{3}{|c|}{$\begin{array}{l}\text { The influence of water deficit on plants } \\
\text { performance described in several species } \\
\text { may be restrictive and even devastating } \\
\text { (Álvarez et al., 2011; Liu et al., 2011). In } \\
\text { our study, after } 8 \mathrm{~d} \text { of progressive drought } \\
\text { stress, T.118 plants still survived. No signif- } \\
\text { icant difference in total day weight was } \\
\text { observed between C and DS-R treatments. } \\
\text { Besides, a significant increase of root to shoot } \\
\text { ratio was found in DS-R plants compared } \\
\text { with C plants after recovery. Such response is }\end{array}$} \\
\hline hyll c & $\mathrm{Chl})$ & \\
\hline $\left.\mathrm{g}^{-1} \mathrm{DW}\right)$ & Proline $\left(\mu \mathrm{g} \cdot \mathrm{g}^{-1} \mathrm{DW}\right)$ & REL (\%) \\
\hline $0.09 \mathrm{a}$ & $73.8 \pm 4.6 \mathrm{~b}$ & $24.4 \pm 1.37 \mathrm{~b}$ \\
\hline $0.06 \mathrm{a}$ & $106 \pm 7.9 \mathrm{a}$ & $46.2 \pm 1.71 \mathrm{a}$ \\
\hline $0.18 \mathrm{a}$ & $73.5 \pm 4.4 \mathrm{~b}$ & $24.5 \pm 3.73 b$ \\
\hline & 150 & \\
\hline & 73.9 & \\
\hline & 117 & \\
\hline & $73.7 \pm 3.5 \mathrm{a}$ & $25.5 \pm 2.99 a$ \\
\hline $0.06 \mathrm{a}$ & $71.5 \pm 2.7 \mathrm{a}$ & $18.9 \pm 3.71 \mathrm{a}$ \\
\hline
\end{tabular}

The influence of water deficit on plants performance described in several species may be restrictive and even devastating (Álvarez et al., 2011; Liu et al., 2011). In our study, after $8 \mathrm{~d}$ of progressive drought stress, T.118 plants still survived. No significant difference in total day weight was observed between $\mathrm{C}$ and DS-R treatments. ratio was found in DS-R plants compared with $\mathrm{C}$ plants after recovery. Such response is

Table 2. Water use efficiency (WUE), relative water content (RWC), specific leaf area (SLA), total chlorophyll contents $\left(\mathrm{Chl}_{\mathrm{t}}\right)$, proline contents, and relative electrolyte leakage (REL) in T.118 plants.

\begin{tabular}{|c|c|c|c|c|c|c|c|c|}
\hline \multicolumn{2}{|l|}{ Days } & Treatments & WUE $\left(\mathrm{mmol} \cdot \mathrm{mol}^{-1}\right)$ & RWC (\%) & $\operatorname{SLA}\left(\mathrm{cm}^{2} \cdot \mathrm{g}^{-1}\right)$ & $\mathrm{Chl}_{\mathrm{t}}\left(\mathrm{mg} \cdot \mathrm{g}^{-1} \mathrm{DW}\right)$ & Proline $\left(\mu \mathrm{g} \cdot \mathrm{g}^{-1} \mathrm{DW}\right)$ & REL (\%) \\
\hline \multirow[t]{4}{*}{$\overline{\text { Drought }}$} & 5 & $\mathrm{C}$ & $2.7 \pm 0.13 b$ & $89.7 \pm 0.7 \mathrm{a}$ & $60.4 \pm 1.23 \mathrm{a}$ & $0.934 \pm 0.09 \mathrm{a}$ & $73.8 \pm 4.6 b$ & $24.4 \pm 1.37 \mathrm{~b}$ \\
\hline & & DS-R & $3.2 \pm 0.16 \mathrm{a}$ & $83.4 \pm 1.2 \mathrm{a}$ & $52.7 \pm 0.73 \mathrm{~b}$ & $1.06 \pm 0.06 \mathrm{a}$ & $106 \pm 7.9 \mathrm{a}$ & $46.2 \pm 1.71 \mathrm{a}$ \\
\hline & 8 & $\mathrm{C}$ & $2.7 \pm 0.11 b$ & $90.0 \pm 2.2 \mathrm{a}$ & $60.2 \pm 1.77 \mathrm{a}$ & $0.927 \pm 0.18 \mathrm{a}$ & $73.5 \pm 4.4 b$ & $24.5 \pm 3.73 b$ \\
\hline & & DS-R & $3.2 \pm 0.47 \mathrm{a}$ & $56.5 \pm 2.3 b$ & $51.3 \pm 0.52 b$ & $0.831 \pm 0.06 \mathrm{~b}$ & $150 \pm 7.3 \mathrm{a}$ & $52.4 \pm 3.62 \mathrm{a}$ \\
\hline \multirow[t]{4}{*}{ Recovery } & 10 & $\mathrm{C}$ & $2.8 \pm 0.08 b$ & $89.5 \pm 0.75 \mathrm{a}$ & $60.3 \pm 1.19 \mathrm{a}$ & $0.928 \pm 0.03 \mathrm{a}$ & $73.9 \pm 4.0 \mathrm{~b}$ & $24.9 \pm 3.62 \mathrm{a}$ \\
\hline & & DS-R & $3.2 \pm 0.25 \mathrm{a}$ & $81.5 \pm 2.5 b$ & $55.9 \pm 1.45 \mathrm{~b}$ & $0.917 \pm 0.02 \mathrm{a}$ & $117 \pm 5.0 \mathrm{a}$ & $38.1 \pm 5.87 \mathrm{a}$ \\
\hline & 17 & $\mathrm{C}$ & $2.7 \pm 0.24 b$ & $89.7 \pm 3.3 \mathrm{a}$ & $59.8 \pm 1.93 \mathrm{a}$ & $0.932 \pm 0.05 \mathrm{a}$ & $73.7 \pm 3.5 \mathrm{a}$ & $25.5 \pm 2.99 \mathrm{a}$ \\
\hline & & DS-R & $2.7 \pm 0.35 \mathrm{~b}$ & $89.7 \pm 1.2 \mathrm{a}$ & $60.7 \pm 1.24 \mathrm{a}$ & $0.934 \pm 0.06 \mathrm{a}$ & $71.5 \pm 2.7 \mathrm{a}$ & $18.9 \pm 3.71 \mathrm{a}$ \\
\hline
\end{tabular}

$\mathrm{C}=$ control; DS- $\mathrm{R}=$ drought-stressed to recovery.

Data are mean $\pm \mathrm{SE}(\mathrm{n}=3)$. Different lowercase letters in each column indicate significant differences $(P<0.05)$ between treatments on each sampling day. 


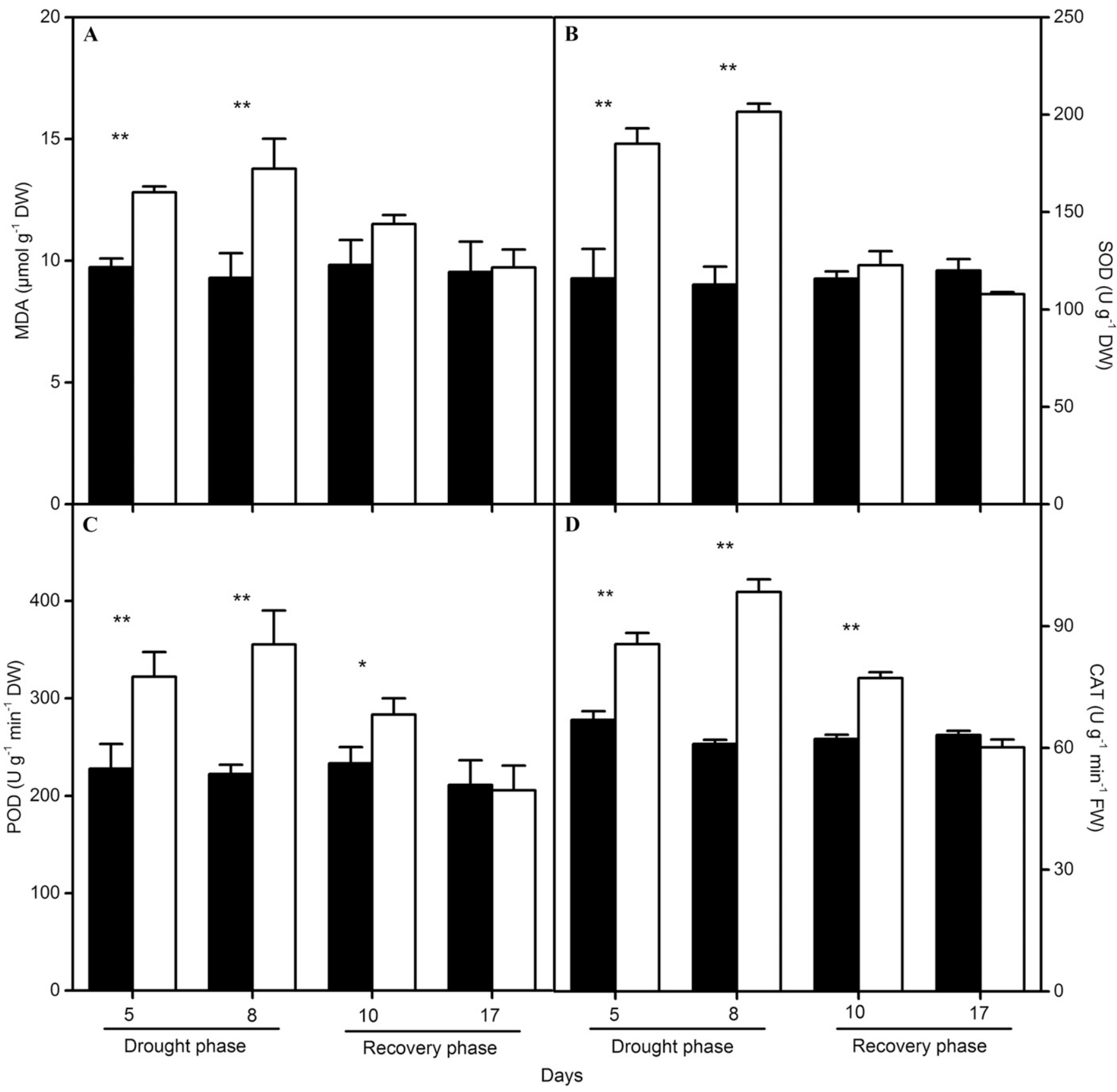

Fig. 4. Variation in mean (and sE, $\mathrm{n}=3)(\mathbf{A})$ malondialdehyde (MDA), $(\mathbf{B})$ superoxide dismutase (SOD), $(\mathbf{C})$ peroxidase (POD), and (D) catalase (CAT) of T.118 in C ( $\square$ ) and DS-R $(\square)$ treatments. ${ }^{*}{ }^{* * *} P<0.05, P<0.01$ between treatments, respectively.

attributable to the development of root systems, because leaf and stem growth is relatively more inhibited than root. Generally under well-watered conditions, plants use a large fraction of light together with adequate moisture for photosynthesis. When drought is superimposed, the balance between light capture and water utilization is broken (Chaves et al., 2003). On one hand, $T .118$ plants enhanced WUE to cope with decreasing water availability. Thus, minimizing water loss in DS-R plants is essential and $g_{\mathrm{S}}$ was reduced as initial acclimation for T.118 plants adapting to water deficit, which occurred together with a remarkable reduction in $T_{\mathrm{r}}$. Furthermore, the dramatic reduction of $P_{\mathrm{n}}$ and $g_{\mathrm{S}}$ and ongoing increase tendency of $C_{\mathrm{i}}$ suggested the predominance of nonstomatal limitations to photosynthesis on day 8. Diminish of leaf RWC is another approach for plants to increase water exploitability, which may finally help to increase carbon investment to root tissues (RosalesSerna et al., 2004). As expected, the leaves of DS-R T.118 plants exhibited large reductions in RWC, especially on day 8. During drought phase, several leaves located on the top branches of $T .118$ plants had been observed to wilt irreversibly due to over dehydration. In addition, correlation analysis suggested that $T .118$ plants lost part of leaf water content at low stomatal aperture.

On the other hand, superimposed drought stress makes it necessary for $T .118$ plants to subtract excrescent light, either preventing absorbing, for instance by rolling leaves to decrease leaf canopy or losing chlorophyll (Havaux and Tardy, 1999), or diverting internal light from photochemistry to thermal dissipation (Chaves et al., 2003). For DS-R plants, reduced SLA on days 5 and 8 was attributed to a strategy that allowed the minimization of light absorption. Meanwhile, decreasing of leaf $\mathrm{Chl}_{\mathrm{t}}$ accompanied by $F_{v} /$ $F_{m}$ and $\varphi$ PSII was observed despite the short duration of drought phase. Such photoinhibition was probably associated with damage caused on the primary electron acceptors of PSII due to water deficit. What is more, photo-protection of the photosynthetic apparatus occurred in DS-R plants on day 8 since 
Table 3. Growth, biomass and root to shoot ration of $T .118$ plants on day 17 .

\begin{tabular}{|c|c|c|c|c|c|c|c|c|c|c|c|}
\hline \multirow[b]{2}{*}{ Treatment } & \multirow[b]{2}{*}{$\mathrm{Ht}(\mathrm{cm})$} & \multirow[b]{2}{*}{$\mathrm{BD}(\mathrm{mm})$} & \multicolumn{4}{|c|}{ Fresh wt (g) } & \multicolumn{4}{|c|}{ Dry wt (g) } & \multirow[b]{2}{*}{ Root to shoot ratio } \\
\hline & & & Root & Stem & Leaf & Total & Root & Stem & Leaf & Total & \\
\hline$\overline{\mathrm{C}}$ & 61.0 & 9.2 & 6.5 & 22.6 & $30.5^{*}$ & $59.6^{*}$ & 3.8 & 6.8 & 8.5 & 19.1 & $0.25 * *$ \\
\hline DS-R & 56.8 & 9.2 & 6.3 & 17.7 & 26.5 & 50.5 & 4.3 & 5.6 & 7.3 & 17.2 & 0.34 \\
\hline
\end{tabular}

$\mathrm{C}=$ control; $\mathrm{BD}=$ basal diameter; $\mathrm{DS}-\mathrm{R}=$ drought-stressed to recovery.

Data are mean of six replicates.

$*, * * P<0.05, P<0.01$ between treatments, respectively.
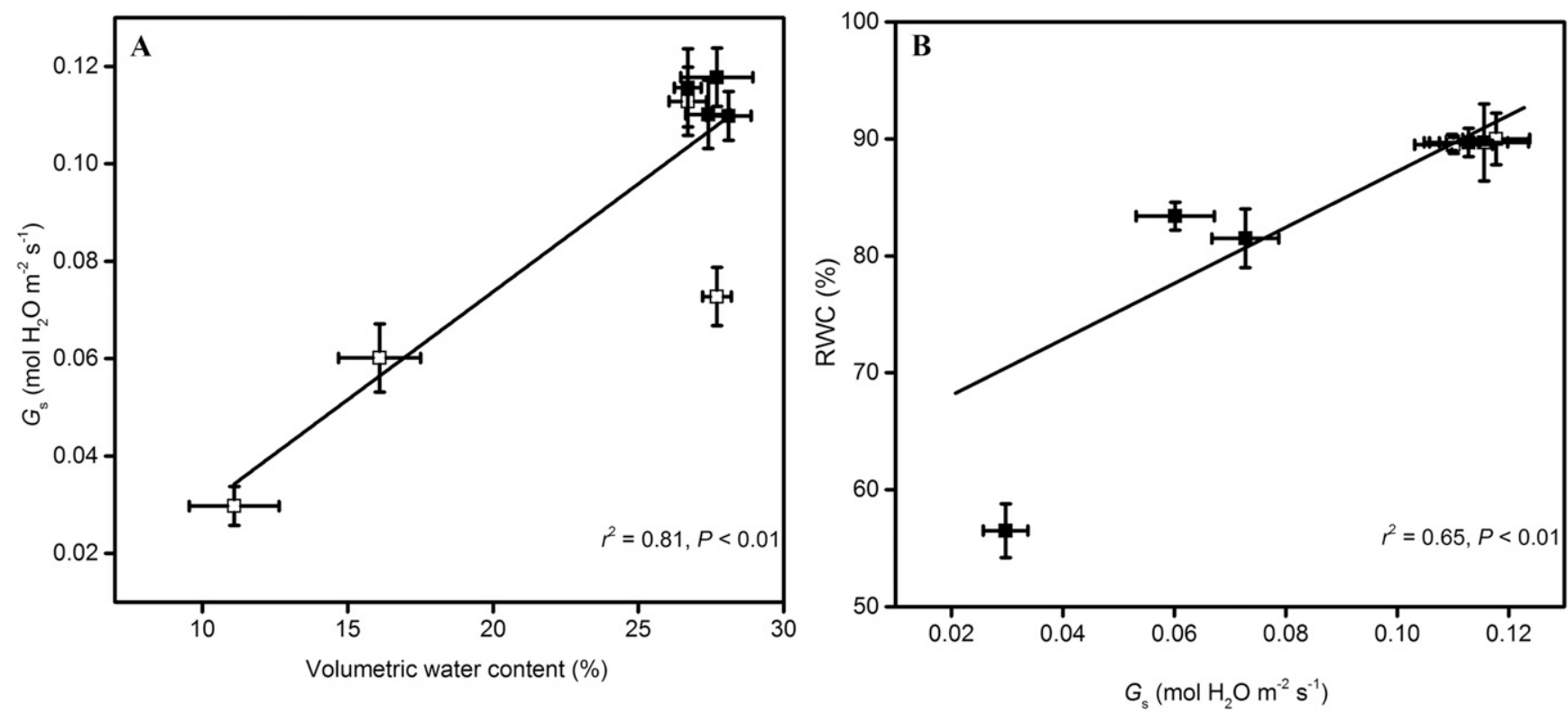

Fig. 5. Relationship between stomatal conductance $\left(g_{\mathrm{S}}\right)$ and (A) soil water content and (B) leaf relative water content (RWC) in $T$.118 plants subjected to C ( $\left.\mathbf{\square}\right)$ and DS-R $(\square)$ treatments. Each square represents samples measured on each sampling day. Bars indicate mean \pm SE, the replications of $g_{\mathrm{S}}$, soil water content, and RWC were 6,6 , and 3 , respectively.

NPQ, which represents the light energy dissipated as heat, reached a maximum value and was significantly higher $(P<0.05)$ than $C$ plants. This result was consistent with previous studies that a similar pattern of photo-protection was employed by barley (Hordeum vulgare) and mango (Mangifera indica), and such a mechanism was more active in drought-tolerant plants (Elsheery and Cao, 2008; Kocheva et al., 2004).

Among the compatible solutes in osmotic adjustment, proline plays a protective role to avoid membrane injury by maintaining cellular turgor (Hare and Cress, 1997). In this experiment, membrane electrolyte leakage of $T .118$ plants had been detected as drought intensified, and contents of proline increased dramatically from days 5 to 8 . So the accumulated proline minimized peroxidation to preserve the protein structure and cell membrane integrity in $T .118$ plants, which indicated remarkable alleviation of cellular hyperosmolarity and ionic disequilibrium induced by severe drought stress (Kishor et al., 2005). At the same time, the antioxidant level of plants, which mainly depends on antioxidant enzymes activities, is indispensable for the stress tolerance development. Under normal growth conditions, the amount of ROS in plants is low and steady. However, drought stress broke such balance in T.118 plants. To relieve drought-induced oxidative stress,
SOD plays a key role in the first threshold of oxidative defense in catalyzing the dismutation of $\mathrm{O}_{2}^{-}$into $\mathrm{H}_{2} \mathrm{O}_{2}$, and then the generated $\mathrm{H}_{2} \mathrm{O}_{2}$ will be eliminated by CAT and POD (Liu et al., 2011; Zhu et al., 2009). For DS-R $T .118$ plants, drought stress enhanced of SOD, POD, and CAT activities, exhibiting cooperative scavenging function to eliminate ROS. What is more, the antioxidant enzymes activities provided higher protection on day 8 against drought stress than day 5 since they kept increasing. Similar evidence of antioxidants to water deficit had been observed in Brassica napus and Sinapis alba, registering low lipid peroxidation levels together with high antioxidant enzyme activities (Xia et al., 2016). In agreement with that, antioxidant enzyme activities in $T .118$ plants would play a vital role in achieving better water deficit tolerance.

Depending on the intensity of drought stress, the recovery of physiological characteristics is progressive and will take several days or more at times (Souza et al., 2004). Although the recovery phase was limited to $9 \mathrm{~d}$, during which T.118 plants did exhibit superior recuperative performance, $8 \mathrm{~d}$ of water deficit did not impair photosynthetic apparatus from the perspective of whole plants, since their photosynthesis was rapidly recovered after rewatering. As Sapeta et al. (2013) suggested, rapid and complete photosynthetic recovery from water deficit is a fundamental aspect of plant persistence, and dictates plant survivability in drought stress conditions with merely sporadic water supply. Likewise, completely restored photosynthesis were reported in other droughttolerant plants after a few days of rewatering, such as oleander (Nerium indicum) and psammophytes (Setaria viridis and Digitaria ciliaris) (Flexas et al., 2006; Luo et al., 2011). At the same time, $\mathrm{Chl}_{\mathrm{t}}$ and fluorescence quickly recovered to pre-drought levels once stress had been relieved, indicating the previous damage caused on photochemistry had been successfully restored.

It is reported that recovery of plants from drought stress is a two-stage process ( $\mathrm{Xu}$ et al., 2013). The primary stage occurs during the first few hours to reopen leaf stoma for gas and water exchange. The second stage lasts a few days, mainly normalizing metabolic function. In T.118 plants, following rewatering, the stomata reopened and the SLA and RWC recovered rapidly. The reason for the full recovery of leaf water relation in $T .118$ plants indicates that vessels were likely rapidly refilled by water. However, a drought tolerant strategy mainly based on reopened stomata was not efficacious enough to ensure rapid recovery (Zwicke et al., 2015). As cluster analysis demonstrated in this experiment, the collaborative defense of osmosis 


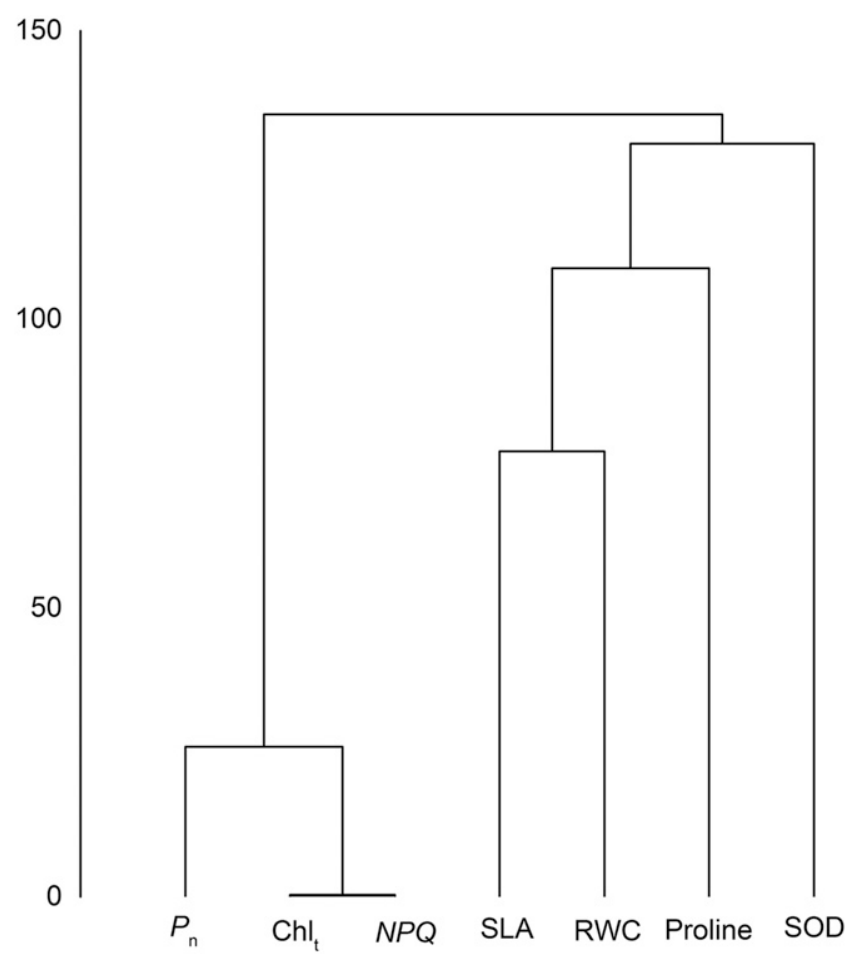

Fig. 6. Dendrogram of the parameters studied. Parameters for analysis were net photosynthetic rate $\left(P_{\mathrm{n}}\right)$, Specific leaf area (SLA), leaf relative water content (RWC), total chlorophyll contents $\left(\mathrm{Chl}_{\mathrm{t}}\right)$, nonphotochemical quenching (NPQ), superoxide dismutase (SOD), and proline.

and antioxidation in $T .118$ plants played another emphasized part. The consistent decreasing trend of proline, SOD, POD, and CAT during recovery phase showed the successful restoration of osmosis and antioxidation. Moreover, persistence of T.118 plants can also be correlated with efficient regain of soil moisture by roots, since root to shoot ratio of T.118 in DS-R plants exhibited significant increase compared with $\mathrm{C}$ plants. Such advantage enhances soil acquisition and manifests a great plasticity in root system against drought stress (Padilla and Pugnaire, 2007).

\section{Conclusion}

Physiological acclimation of T.118 plants to short-term drought stress included elevated WUE by stomatal closure, decreasing of $P_{\mathrm{n}}, T_{\mathrm{r}}$, leaf area, $\mathrm{Chl}_{\mathrm{t}}$, and thermal dissipation. Meanwhile, accumulation of proline and antioxidases helped to maintain cell turgor and metabolic functions. After rewatering, these adaptions eventually returned to normal levels. Accordingly, we conclude that the T.118 plants have a high degree of plasticity in response to water deficit. These combined strategies enable $T .118$ plants to survive in short-term or stochastic drought conditions with unpredictable precipitation.

\section{Literature Cited}

Adams, R.P., M.A. Arnold, A.R. King, and C. David. 2012. Taxodium (Cupressaceae): One, two or three species? Evidence from DNA sequences and terpenoids. Phytologia 94:159-168.

Allen, C.D., A.K. M acalady, H. Chenchouni, D. Bachelet, N. McDowell, M. Vennetier-Kitzberger,
T. Rigling, D.D. Breshears, E.T. Hogg, G. Patrick, R. Fensham, Z. Zhen, C. Jorge, D. Natalia, L. Jong-Hwan, A. Gillian, W. Steven, S. Akkin, and C. Neil. 2010. A global overview of drought and heat-induced tree mortality reveals emerging climate change risks for forests. For. Ecol. Mgt 259:660-684.

Álvarez, S., A. Navarro, E. Nicolás, and M.J. Sánchez-Blanco. 2011. Transpiration, photosynthetic responses, tissue water relations and dry mass partitioning in Callistemon plants during drought conditions. Sci. Hort. 129:306-312.

Bates, L., R. Waldren, and I. Teare. 1973. Rapid determination of free proline for water-stress studies. Plant Soil 39:205-207.

Blum, A. and A. Ebercon. 1981. Cell membrane stability as a measure of drought and heat tolerance in wheat. Crop Sci. 21:43-47.

Chaves, M.M., J.P. Maroco, and J.S. Pereira. 2003. Understanding plant responses to droughtFrom genes to the whole plant. Funct. Plant Biol. 30:239-264.

Chen, D., S. Wang, B. Cao, D. Cao, G. Leng, H. Li, and X. Deng. 2015. Genotypic variation in growth and physiological response to drought stress and re-watering reveals the critical role of recovery in drought adaptation in maize seedlings. Front. Plant Sci. 6:1241.

Corcuera, L., J. Camarero, and E. Gil-Pelegrín. 2002. Functional groups in Quercus species derived from the analysis of pressure-volume curves. Trees (Berl.) 16:465-472.

Creech, D., L. Zhou, Y. Yunlong, and T. EguiluzPiedra. 2011. Can Taxodium be improved? Arnoldia 69:11-20.

Denny, G.C. and M.A. Arnold. 2007. Taxonomy and nomenclature of baldcypress, pondcypress, and montezuma cypress: One, two, or three species? HortTechnology 1:125-127.

Elsheery, N.I. and K.-F. Cao. 2008. Gas exchange, chlorophyll fluorescence, and osmotic adjustment in two mango cultivars under drought stress. Acta Physiol. Plant. 30:769-777.

Fischer, J., J. Stott, A. Zerger, G. Warren, K Sherren, and R.I. Forrester. 2009. Reversing a tree regeneration crisis in an endangered ecoregion. P. Natl. A. Sci. India 106:1038610391.

Flexas, J., J. Bota, J. Galmes, H. Medrano, and M. Ribas-Carbó. 2006. Keeping a positive carbon balance under adverse conditions: Responses of photosynthesis and respiration to water stress. Physiol. Plant. 127:343-352.

Gallé, A., P. Haldimann, and U. Feller. 2007. Photosynthetic performance and water relations in young pubescent oak (Quercus pubescens) trees during drought stress and recovery. New Phytol. 174(4):799-810.

Gianoli, E. and M. González-Teuber. 2005. Environmental heterogeneity and population differentiation in plasticity to drought in Convolvulus chilensis (Convolvulaceae). Evol. Ecol. 19:603613.

Hare, P. and W. Cress. 1997. Metabolic implications of stress-induced proline accumulation in plants. Plant Growth Regulat. 21:79-102.

Havaux, M. and F. Tardy. 1999. Loss of chlorophyll with limited reduction of photosynthesis as an adaptive response of Syrian barley landraces to high-light and heat stress. Funct. Plant Biol. 26:569-578.

Johnson, S.M., S.J. Doherty, and R.R.D. Croy. 2003. Biphasic superoxide generation in potato tubers. A self-amplifying response to stress. Plant Physiol. 3:1440-1449.

Kishor, P.K., S. Sangam, R. Amrutha, P.S. Laxmi, K. Naidu, K. Rao, S. Rao, K. Reddy, P. Theriappan, and N. Sreenivasulu. 2005. Regulation of proline biosynthesis, degradation, uptake and transport in higher plants: Its implications in plant growth and abiotic stress tolerance. Curr. Sci. 88:424-438.

Kocheva, K., P. Lambrev, G. Georgiev, V. Goltsev, and M. Karabaliev. 2004. Evaluation of chlorophyll fluorescence and membrane injury in the leaves of barley cultivars under osmotic stress. Biol. Chem. 63:121-124.

Laanisto, L. and Ü. Niinemets. 2015. Polytolerance to abiotic stresses: How universal is the shadedrought tolerance trade-off in woody species? Glob. Ecol. Biogeogr. 24:571-580.

Liu, C., Y. Liu, K. Guo, D. Fan, G. Li, Y. Zheng, L. $\mathrm{Yu}$, and R. Yang. 2011. Effect of drought on pigments, osmotic adjustment and antioxidant enzymes in six woody plant species in karst habitats of southwestern China. Environ. Exp. Bot. 71:174-183.

Lopes, M.S., J.L. Araus, P.D. Van-Heerden, and C.H. Foyer. 2011. Enhancing drought tolerance in C4 crops. J. Expt. Bot. 62:3135-3153.

Luo, Y., X. Zhao, R. Zhou, X. Zuo, J. Zhang, and Y. Li. 2011. Physiological acclimation of two psammophytes to repeated soil drought and rewatering. Acta Physiol. Plant. 33(1):79-91.

McDowell, N.G. 2011. Mechanisms linking drought, hydraulics, carbon metabolism, and vegetation mortality. Plant Physiol. 155:1051-1059.

Padilla, F. and F. Pugnaire. 2007. Rooting depth and soil moisture control Mediterranean woody seedling survival during drought. Funct. Ecol. 21:489-495.

Perron, M. 2008. A strategy for the second breeding cycle of Larix x marschlinsii in Quebec, Canada including experiments to guide interspecific tree breeding programme. Silvae Genet. 57:282.

Qi, B., Y. Yang, Y. Yin, M. Xu, and H. Li. 2014. De novo sequencing, assembly, and analysis of the Taxodium 'Zhongshansa' roots and shoots 
transcriptome in response to short-term waterlogging. BMC Plant Biol. 14:201.

Ritchie, R. 2008. Universal chlorophyll equations for estimating chlorophylls a, b, c, and d and total chlorophylls in natural assemblages of photosynthetic organisms using acetone, methanol, or ethanol solvents. Photosynthetica 46:115-126.

Rosales-Serna, R., J. Kohashi-Shibata, J.A. AcostaGallegos, C. Trejo-López, J. Ortiz-Cereceres, and J.D. Kelly. 2004. Biomass distribution, maturity acceleration and yield in droughtstressed common bean cultivars. Field Crops Res. 85:203-211.

Rouphael, Y., M. Cardarelli, G. Colla, and E. Rea. 2008. Yield, mineral composition, water relations, and water use efficiency of grafted mini-watermelon plants under deficit irrigation. HortScience 43:730-736.

Sapeta, H., J.M. Costa, T. Lourenço, J. Maroco, P. Van der Linde, and M.M. Oliveira. 2013. Drought stress response in Jatropha curcas: Growth and physiology. Environ. Exp. Bot. 85:76-84.

Selote, D.S. and R. Khanna-Chopra. 2010. Antioxidant response of wheat roots to drought acclimation. Protoplasma 1-4:153-163.

Sharma, D.K., A. Dubey, M. Srivastav, A. Singh, R. Sairam, R.A. Pandey-Dahuja, and C. Kaur. 2011. Effect of putrescine and paclobutrazol on growth, physiochemical parameters, and nutrient acquisition of salt-sensitive citrus rootstock
Karna khatta (Citrus karna Raf.) under $\mathrm{NaCl}$ stress. J. Plant Growth Regul. 30:301-311.

Souza, R., E. Machado, J. Silva, A. Lagôa, and J. Silveira. 2004. Photosynthetic gas exchange, chlorophyll fluorescence and some associated metabolic changes in cowpea (Vigna unguiculata) during water stress and recovery. Environ. Exp. Bot. 51:45-56.

Toscano, S., D. Scuderi, F. Giuffrida, and D. Romano. 2014. Responses of Mediterranean ornamental shrubs to drought stress and recovery. Sci. Hort. 178:145-153.

Tsumura, Y., N. Tomaru, Y. Suyama, and S. Bacchus. 1999. Genetic diversity and differentiation of Taxodium in the south-eastern United States using cleaved amplified polymorphic sequences. Heredity 83:229-238.

Verbruggen, N. and C. Hermans. 2008. Proline accumulation in plants: A review. Amino Acids 4:753-759.

Xia, L., L. Yang, N. Sun, J. Li, Y. Fang, and Y. Wang. 2016. Physiological and antioxidant enzyme gene expression analysis reveals the improved tolerance to drought stress of the somatic hybrid offspring of Brassica napus and Sinapis alba at vegetative stage. Acta Physiol. Plant. 38:1-10.

Xu, L., J. Yu, L. Han, and B. Huang. 2013. Photosynthetic enzyme activities and gene expression associated with drought tolerance and post-drought recovery in Kentucky bluegrass. Environ. Exp. Bot. 89:28-35.
Yazaki, K., K. Kuroda, T. Nakano, M. Kitao, H. Tobita, M.Y. Ogasa, and A. Ishida. 2015. Recovery of physiological traits in saplings of invasive Bischofia tree compared with three species native to the Bonin Islands under successive drought and irrigation cycles. PLoS One 10:e0135117.

Yin, Y. and C. Yu. 2005. Hybridization between Taxodium species. China Forestry Publishing House, Beijing, China (in Chinese).

Yin, Y., C. Yu, J. Hua, J. Huan, L. Han, B. Qi, and P. Ren. 2014. A trial on the silviculture of Taxodium hybrid 'Zhongshanshan 118' planted in the hydro-fluctuation belt of the three Gorges Reservoir in Chongqing City. China Forestry Sci. Tech. 28:110-114 (in Chinese).

Zhou, L., D.L. Creech, K.W. Krauss, Y. Yunlong, and D.L. Kulhavy. 2010. Can we improve the salinity tolerance of genotypes of Taxodium by using varietal and hybrid crosses? HortScience 45:1773-1778.

Zhu, J.J., J.L. Zhang, H.C. Liu, and K.F. Cao. 2009. Photosynthesis, non-photochemical pathways and activities of antioxidant enzymes in a resilient evergreen oak under different climatic conditions from a valley-savanna in Southwest China. Physiol. Plant. 135:62-72.

Zwicke, M., C. Picon-Cochard, A. Morvan-Bertr, M.P. Prud'homme, and F. Volaire. 2015. What functional strategies drive drought survival and recovery of perennial species from upland grassland? Ann. Bot. (Lond.) 116:1001. 